\title{
Ofatumumab, a fully human anti-CD20 monoclonal antibody, in biological-naive, rheumatoid arthritis patients with an inadequate response to methotrexate: a randomised, double-blind, placebo-controlled clinical trial
}

\author{
Peter C Taylor, ${ }^{1}$ Emilia Quattrocchi, ${ }^{2}$ Stephen Mallett, ${ }^{2}$ Regina Kurrasch, ${ }^{3}$ \\ Jørgen Petersen, ${ }^{4}$ David J Chang ${ }^{3}$
}

- An additional supplementary table is published online only. To view this file please visit the journal online at (http://ard. bmj.com)

${ }^{1}$ Kennedy Institute of Rheumatology Division, Imperial College, London, UK ${ }^{2}$ GlaxoSmithKline Clinical Development, Stockley Park, UK ${ }^{3}$ GlaxoSmithKline Clinical Development, Upper Merion, Pennsylvania, USA

${ }^{4}$ Genmab, Copenhagen, Denmark

\section{Correspondence to}

Professor Peter Taylor, Kennedy Institute of Rheumatology Division, Imperial College, London, UK; peter.c.taylor@imperial.ac.uk

Accepted 17 July 2011 Published Online First 22 August 2011

\section{UNLOCKE}

This paper is freely available online under the BMJ Journals unlocked scheme, see http:// ard.bmj.com/info/unlocked.dtl

\section{ABSTRACT}

Objectives To evaluate the efficacy and safety of intravenous ofatumumab, a fully human anti-CD20 monoclonal antibody, in biological-naive, active rheumatoid arthritis (RA) patients despite methotrexate treatment.

Methods In this double-blind, placebo-controlled, phase III study, active RA patients on stable methotrexate were randomly assigned to one course of two infusions of ofatumumab $700 \mathrm{mg}(n=130)$ or placebo $(n=130)$, 2 weeks apart. The primary endpoint was the ACR20 response at week 24 . Secondary endpoints included ACR50/70, EULAR response, disease activity score based on 28 joints using C-reactive protein, adverse events (AE) and immunogenicity.

Results At week 24, a greater proportion of patients on ofatumumab compared with placebo achieved an ACR20 response ( $50 \%$ vs $27 \%, p<0.001)$ and a good or moderate EULAR response (67\% vs $41 \%, p<0.001)$. All other key secondary efficacy endpoints were significantly improved on ofatumumab. Efficacy observed by 8 weeks was sustained throughout the study. The most common AE for ofatumumab versus placebo were rash $(21 \%$ vs $<1 \%$ ) and urticaria (12\% vs $<1 \%$ ), mostly occurring on the first infusion day. Overall, first-dose infusion reactions were $68 \%$ for ofatumumab and $6 \%$ for placebo, mostly mild to moderate; second-dose infusion reactions markedly declined ( $<1 \%$ and $0 \%$ ). Serious AE were reported in $5 \%$ of ofatumumab versus $3 \%$ of placebo patients. Infection rates were $32 \%$ and $26 \%$ (serious infections $<1 \%$ and $2 \%$ ), respectively. One death (interstitial lung disease), unrelated to study drug, was reported on ofatumumab. No antidrug antibodies were detected in ofatumumab patients.

Conclusions Ofatumumab significantly improved all clinical outcomes in biological-naive, active RA patients with no detectable immunogenicity at week 24 . No unexpected safety findings were identified. Trial Registry clinical trials.gov registration number NCT00611455

Ofatumumab (HuMax-CD20) is a human IgG1א lytic monoclonal antibody ( $\mathrm{mAb}$ ) that specifically binds to the human CD20 antigen inducing potent B-cell lysis. The CD20 antigen is expressed only by $B$ lymphocytes from the pre- $B$ to the plasmacytoid immunoblast stage. Ofatumumab recognises a unique membrane-proximal epitope on the human CD20 molecule, distinct from the epitope recognised by rituximab ${ }^{1}$ or by other anti-CD20 mAb. ${ }^{2}$ The membrane proximity of this epitope probably accounts for the high efficiency of B-cell killing observed with ofatumumab in both in-vitro and in-vivo preclinical studies. ${ }^{4-7}$

In animal models, ofatumumab induced selective and prolonged B-cell depletion primarily mediated by effective complement-dependent cytotoxicity and antibody-dependent cell-mediated cytotoxicity. $^{8} 9$ Effective complement-dependent cytotoxicity may depend on the distance between the plasma membrane and the constant parts of the sensitising antibody thus enabling the efficient and rapid engagement of complement activation. ${ }^{10}$

A phase I/II study of ofatumumab, administered as two intravenous infusions of 300,700 or $1000 \mathrm{mg}$ 2 weeks apart, in active rheumatoid arthritis (RA) patients with an inadequate response to diseasemodifying antirheumatic drugs (DMARD), demonstrated significant clinical benefit and reasonable tolerability (improved after the implementation of premedication) at all doses investigated when compared with placebo, with the $700 \mathrm{mg}$ dose considered to be optimal. ${ }^{11}$

To characterise further the efficacy and safety profile of ofatumumab we conducted a placebocontrolled phase III trial in patients with active RA who had an inadequate response to methotrexate therapy and no previous biological treatment exposure. This trial was also designed to investigate the effects of ofatumumab on the extent and duration of B-cell depletion, biomarkers of clinical response, patient-reported outcomes and immunogenicity.

\section{METHODS}

\section{Study design and objectives}

This was a multicentre, randomised, doubleblind, placebo-controlled, parallel group, phase III trial. Patients were enrolled at 36 sites in western Europe, eastern Europe, South America and Asia Pacific. The trial is registered at clinicaltrials. gov number NCT00611455. The first patient was enrolled in January 2008 and the last visit for the double-blind phase was in June 2009. The trial was conducted in accordance with good clinical practice and the Declaration of Helsinki. All participating sites received approval from national, regional, or investigational centre ethics committee 
or institutional review boards; each patient provided written informed consent.

The trial included a 24-week double-blind, placebo-controlled period followed by a 120 -week open-label extension and a safety follow-up. This paper summarises results from the completed, placebo-controlled, 24-week double-blind phase only.

Eligible patients were randomly assigned (1:1) to receive two infusions of either ofatumumab $700 \mathrm{mg}$ or placebo 2 weeks apart (one course), added to their stable background methotrexate dose. Randomisation was stratified by rheumatoid factor (RF) seropositivity/negativity and region. GlaxoSmithKline prepared a computer-generated randomisation schedule and randomisation was handled centrally through an interactive voice response system. An unblinded pharmacist at each site prepared the infusions; ofatumumab and saline (placebo) infusions were indistinguishable. Other study personnel and patients were blinded to treatment allocation until the double-blind period was complete. Premedication with antihistamine (certirizine $10 \mathrm{mg}$ or equivalent), oral paracetamol $1000 \mathrm{mg}$ and intravenous methylprednisolone $100 \mathrm{mg}$ was administered $30 \mathrm{~min}$ to $2 \mathrm{~h}$ before each infusion. Patients who did not respond were allowed nonbiological DMARD rescue treatment from week 16; however, the use of rescue treatment precluded subsequent entry into the open-label period. Breakthrough pain management such as analgesics, non-steroidal anti-inflammatory drugs and one intraarticular corticosteroid injection in one joint per 6-month period were allowed. The joint receiving an intra-articular injection was scored as both swollen and tender in joint count assessments during the following 12 -week period.

The primary objective was to evaluate the efficacy of ofatumumab compared with placebo based on the proportion of patients achieving an American College of Rheumatology (ACR) $20^{12}$ response at week 24 . Secondary endpoints included proportions of patients achieving ACR50, ACR70, European League Against Rheumatism (EULAR) good or moderate responses, ${ }^{13}$ and mean changes in the disease activity score based on 28 joints (DAS28) using C-reactive protein (CRP), ${ }^{14}$ health assessment questionnaire disability index (HAQ-DI), ${ }^{15}$ short-form health survey (SF-36v2) and functional assessment of chronic illness therapy-fatigue version $4\left(\right.$ FACIT-F) ${ }^{16}$ at week 24.

\section{Patient population}

Male and non-pregnant, non-lactating female patients 18 years and older, diagnosed with active RA according to ACR 1987 criteria $^{17}$ (RA functional class I, II or III) of 6 months or more duration were eligible to participate. Active RA was defined as eight or more swollen and eight or more tender joint counts, based on $66 / 68$ joint count; either CRP of $1.0 \mathrm{mg} / \mathrm{dl}$ or greater or erythrocyte sedimentation rate (ESR) of $22 \mathrm{~mm} / \mathrm{h}$ or greater; and DAS28 based on ESR of 3.2 or greater. Patients were required to have an inadequate response to methotrexate and to be receiving methotrexate $7.5-25 \mathrm{mg} /$ week for at least 12 weeks, and at a stable dose for at least 4 weeks, before baseline. All patients underwent a washout period of at least 4 weeks for all DMARD (leflunomide $\geq 12$ weeks or administration of cholestyramine treatment for washout according to the manufacturer's instructions) but maintained their concomitant stable methotrexate therapy, along with folic acid of $5 \mathrm{mg} /$ week or greater. Oral corticosteroids ( $\leq 10 \mathrm{mg} /$ day of prednisolone equivalent), nonsteroidal anti-inflammatory drugs and one intra-articular injection of corticosteroid ( $80 \mathrm{mg}$ methylprednisolone or equivalent) in a single joint were permitted. Key exclusion criteria comprised previous exposure to any biological and B-cell-depleting therapy, other autoimmune diseases, significant concurrent, uncontrolled medical conditions, neutrophils less than $2 \times 10^{9} / 1$, platelets less than $100 \times 10^{9} / 1$, IgG less than $6.94 \mathrm{~g} / 1$ (below lower limits of normal), and positive serology for HIV, hepatitis B or $\mathrm{C}$ infection. Patients were screened for JC virus using PCR for JC viral DNA (Quest Diagnostics, Van Nuys, CA, USA and Heston, Middlesex, UK) and were excluded if tested positive.

\section{Assessments}

Clinical assessments of disease activity were performed at baseline and every 4 weeks to week 24 and included an evaluation of the 68-joint tender joint count and 66-joint swollen joint count conducted by an independent assessor (blinded to patient-rated outcomes), patient's pain assessment (visual analogue scale (VAS) 0-100 mm), patient's and physician's global assessment of disease activity (VAS 0-100 mm), HAQ-DI and levels of acute-phase reactants (ESR and CRP). From these data, ACR20, ACR50 and ACR70 response rates, mean change in DAS28-ESR and DAS28-CRP and EULAR response were determined. FACIT-F and SF-36v2 were assessed at baseline, week 16 and week 24.

Laboratory investigations included levels of peripheral B lymphocytes measured by fluorescence-activated cell sorting analysis by the surrogate marker CD19, peripheral T lymphocytes measured by CD3, CD4 and CD8 markers, immunoglobulins (IgA, $\operatorname{Ig} M, \operatorname{Ig} G$ ), RF and immunoglobulins to RF (IgM-RF, IgG-RF and IgA-RF), anticyclic citrullinated peptide antibodies (anti-CCP), acute phase serum amyloid A, interleukin 6 (IL-6) (all performed by Quest Diagnostics) and antibodies to ofatumumab measured using a validated electrochemiluminescence meso-scale discovery immunoassay. Positive samples from the binding antibody assay were tested in a neutralising antibody assay (Clinical Immunology, Biopharm R\&D, GlaxoSmithKline, King of Prussia, PA, USA).

Adverse events (AE) and serious adverse events (SAE) were collected throughout the study and coded using the Medical Dictionary for Regulatory Activities (MedDRA) version 12. Infusion-related events occurring during study drug infusion and up to $24 \mathrm{~h}$ after completion of the infusion (and likely to represent clinical signs and symptoms characteristic of ofatumumab infusion reactions in patients with RA) were identified by a safety review team before unblinding. Low CD19 cell counts were not reported as $\mathrm{AE}$ and hospitalisation for completion of an infusion was not reported as a SAE. Infections were determined using the MedDRA system organ class infections and infestations'.

\section{Sample size estimation}

A sample size of 124 subjects per group was estimated to provide at least $90 \%$ power to detect differences in the proportions of patients achieving an ACR20 response at week 24 between ofatumumab versus placebo, at a $5 \%$ level of significance. This was based on a $\chi^{2}$ test comparing two binomial proportions.

\section{Statistical analysis}

For categorical endpoints, the efficacy of ofatumumab versus placebo was analysed using the Cochran Mantel Haenszel test, adjusting for baseline stratification factors, RF status and geographical region (ie, eastern Europe, western Europe, South America, Asia Pacific). For continuous endpoints efficacy was analysed using analysis of covariance, adjusting for RF status, geographical region and baseline value. For categorical endpoints, patients who took disallowed medication or withdrew 
from the study were imputed as non-responders. For continuous endpoints, data were imputed by carrying forward the last value recorded before taking disallowed medication or withdrawal (last observation carried forward). The intent-to-treat (ITT) population comprised all randomly assigned patients who received at least one infusion of the study drug. The safety population was identical to the ITT population except that patients were analysed according to their actual treatment in case this differed from their randomised treatment.

\section{RESULTS}

\section{Disposition of patients and baseline characteristics}

A total of 344 patients was screened and 265 were enrolled and randomly assigned; the reasons for screening failure are shown in figure 1. Of the 265 randomly assigned patients, 260 (98\%) were exposed to investigational product and were included in the safety and ITT populations (figure 1). One patient was randomly assigned to placebo but received ofatumumab and was included in the placebo group for the ITT population (based on randomised treatment) and in the ofatumumab group for the safety population (based on actual treatment received).

Demographics and baseline RA characteristics were balanced between the two groups (table 1). Most patients were women $(82 \%)$ and RF positive (84\%), with a mean age of 53 years. At baseline, mean RA duration was 8.5 years, mean DAS28-CRP was 5.7 and mean DAS28-ESR was 6.5 (table 1).

\section{Clinical response}

At week 24, a greater proportion of patients administered ofatumumab $700 \mathrm{mg}$ achieved the primary endpoint of ACR20 compared with placebo $(50 \%$ and $27 \%$, respectively, $\mathrm{p}<0.001)$. In addition, significantly greater improvements in ACR50 and ACR70 were observed with ofatumumab versus placebo (ACR50 27\% and 11\%, p<0.001; ACR70 13\% and $2 \%, p=0.001$ ) (table 2 and figure 2 ). When examined by
RF status, the ACR20 response in ofatumumab and placebo groups, respectively, was $50 \%(54 / 108)$ versus $26 \%(29 / 111)$ for seropositive patients and $48 \%(10 / 21)$ versus $30 \%(6 / 20)$ for seronegative patients. When examined by anti-CCP status,

Table 1 Demographics and baseline disease characteristics

\begin{tabular}{|c|c|c|}
\hline Characteristic & Ofatumumab $700 \mathrm{mg}(\mathrm{n}=129)$ & Placebo $(n=131)$ \\
\hline Mean (SD) age, years & $51.7(11.24)$ & $53.6(11.50)$ \\
\hline Female, n (\%) & $106(82.2)$ & $108(82.4)$ \\
\hline Caucasian, n (\%) & $122(94.6)$ & $129(98.5)$ \\
\hline $\begin{array}{l}\text { Mean (SD) disease } \\
\text { duration, years }\end{array}$ & $7.93(7.230)$ & $9.07(8.987)$ \\
\hline $\begin{array}{l}\text { Median (min, max) } \\
\text { methotrexate dose, mg/week }\end{array}$ & $15.0(7.5,25)$ & $15.0(7.5,25)$ \\
\hline \multicolumn{3}{|l|}{ Previous DMARD, n (\%) } \\
\hline $1-2$ & $87(67.4)$ & $88(67.2)$ \\
\hline $3-4$ & $36(27.9)$ & $32(24.4)$ \\
\hline$>4$ & $6(4.7)$ & $11(8.4)$ \\
\hline $\begin{array}{l}\text { Patients receiving oral } \\
\text { corticosteroid, } \mathrm{n}(\%)\end{array}$ & $75(58.1)$ & $84(64.1)$ \\
\hline $\begin{array}{l}\text { Median (min, max) oral } \\
\text { corticosteroid dose, mg/day* }\end{array}$ & $6.4(1.6,15.0)$ & $5.0(1.6,12.8)$ \\
\hline RF positive, n (\%) & $108(83.7)$ & $111(84.7)$ \\
\hline Median (min, max) CRP, mg/l & $8.3(0,98)$ & $8.3(0,68)$ \\
\hline Mean (SD) ESR, mm/h & $47.1(25.38)$ & $44.4(23.69)$ \\
\hline Mean (SD) total RF, IU/ml ${ }^{\dagger}$ & $326.5(593.60)$ & $250.4(492.71)$ \\
\hline Mean (SD) SJC (66 joints) & $16.2(7.41)$ & $15.7(6.88)$ \\
\hline Mean (SD) TJC (68 joints) & $28.7(13.36)$ & $26.6(12.59)$ \\
\hline Mean (SD) DAS28-CRP & $5.83(0.794)$ & $5.63(0.800)$ \\
\hline Mean (SD) DAS28-ESR & $6.59(0.828)$ & $6.41(0.782)$ \\
\hline Mean (SD) HAO-DI & $1.7(0.67)$ & $1.5(0.65)$ \\
\hline Mean (SD) FACIT-F & $25.2(10.00)$ & $29.5(9.54)$ \\
\hline
\end{tabular}

*Prednisolone equivalent dose.

${ }^{\dagger}$ At screening.

CRP, C-reactive protein; DAS28, disease activity score based on 28 joints; DMARD, disease-modifying antirheumatic drug; ESR, erythrocyte sedimentation rate; FACIT-F, functional assessment of chronic illness therapy-fatigue; HAO-DI, health assessment questionnaire disability index; RF, rheumatoid factor; SJC, swollen joint count; TJC, tender joint count.

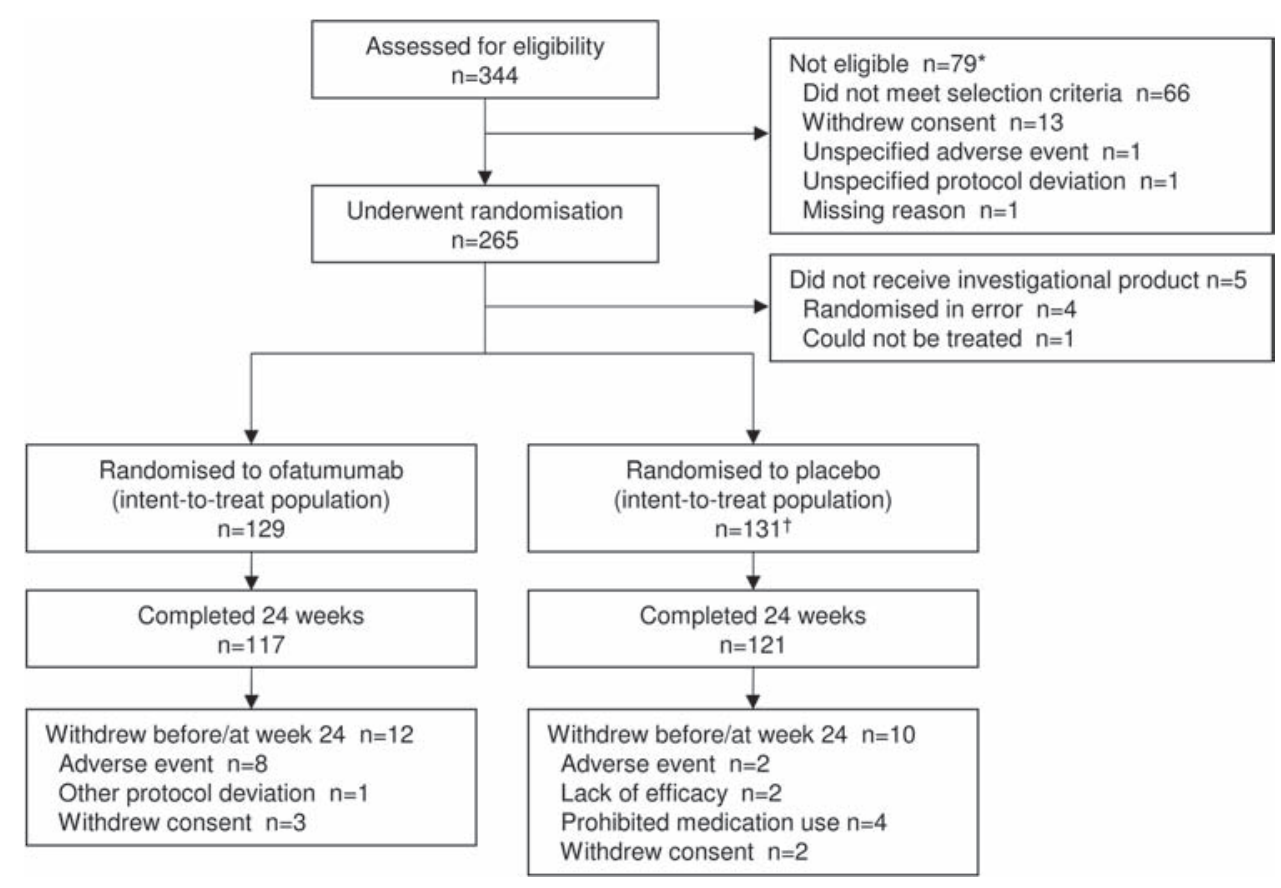

Figure 1 Disposition of patients up to week 24. *Patients could have more than one reason for screening failure. †One patient was randomly assigned to placebo but received ofatumumab. This patient is included in the placebo group for the intent-to-treat population, but in the ofatumumab group for the safety population. 
Table 2 Summary of disease-activity and quality-of-life clinical endpoints at week 24 for patients receiving ofatumumab or placebo

\begin{tabular}{|c|c|c|c|c|}
\hline & Ofatumumab $700 \mathrm{mg}(\mathrm{n}=129)$ & Placebo $(n=131)$ & OR (95\% Cl) & p Value \\
\hline ACR20 & $64 / 129(50 \%)$ & $35 / 131(27 \%)$ & 2.86 (1.67 to 4.91$)$ & $<0.001$ \\
\hline ACR50 & $35 / 129(27 \%)$ & 14/131 (11\%) & 3.29 (1.63 to 6.62$)$ & $<0.001$ \\
\hline ACR70 & $17 / 129(13 \%)$ & $3 / 131(2 \%)$ & $6.63(1.87$ to 23.51$)$ & 0.001 \\
\hline Clinical remission ${ }^{\dagger}$ & $13 / 129(10 \%)$ & $7 / 131(5 \%)$ & 2.09 (0.76 to 5.77$)$ & 0.152 \\
\hline \multirow[t]{2}{*}{ HAQ-DI response ${ }^{\ddagger}$} & $74 / 129$ (57\%) & $59 / 131(45 \%)$ & $1.65(1.01$ to 2.70$)$ & 0.046 \\
\hline & Ofatumumab $700 \mathrm{mg}(\mathrm{n}=129)$ & Placebo $(n=131)$ & Adjusted mean difference (95\% Cl) & p Value \\
\hline Baseline, mean (SD) & $5.83(0.794)$ & $5.63(0.800)$ & & \\
\hline Week 24, mean (SD) & $4.12(1.270)$ & $4.98(1.437)$ & & \\
\hline Adjusted mean (SE) change & $-1.77(0.151)$ & $-0.77(0.154)$ & $-1.00(-1.29$ to -0.72$)$ & $<0.001$ \\
\hline \multicolumn{5}{|l|}{ DAS28-ESR ${ }^{\S}$} \\
\hline Baseline, mean (SD) & $6.59(0.828)$ & $6.41(0.782)$ & & \\
\hline Week 24, mean (SD) & $4.84(1.360)$ & $5.67(1.439)$ & & \\
\hline Adjusted mean (SE) change & $-1.79(0.157)$ & $-0.80(0.161)$ & $-0.99(-1.29$ to -0.69$)$ & $<0.001$ \\
\hline \multicolumn{5}{|l|}{ FACIT-F ${ }^{\pi}$} \\
\hline Baseline, mean (SD) & $25.2(10.00)$ & $29.5(9.54)$ & & \\
\hline Week 24, mean (SD) & $32.0(11.52)$ & $30.2(10.86)$ & & \\
\hline Adjusted mean (SE) change & $7.29(1.353)$ & $3.55(1.394)$ & 3.75 (1.11 to 6.39$)$ & 0.006 \\
\hline \multicolumn{5}{|c|}{ SF-36 physical component summary score ${ }^{* *}$} \\
\hline Baseline, mean (SD) & $29.9(6.73)$ & $31.9(7.32)$ & & \\
\hline Week 24, mean (SD) & $35.9(9.28)$ & $34.8(8.79)$ & & \\
\hline Adjusted mean (SE) change & $6.69(1.031)$ & $4.21(1.048)$ & $2.48(0.51$ to 4.45$)$ & 0.014 \\
\hline \multicolumn{5}{|c|}{ SF-36 mental component summary score ${ }^{* *}$} \\
\hline Baseline, mean (SD) & $38.2(11.77)$ & $40.1(11.84)$ & & \\
\hline Week 24, mean (SD) & $42.2(11.38)$ & $40.2(11.95)$ & & \\
\hline Adjusted mean (SE) change & $4.60(1.272)$ & $1.57(1.308)$ & $3.03(0.61$ to 5.46$)$ & 0.014 \\
\hline
\end{tabular}

ACR20/50/70, 20\%/50\%/70\% improvement as per American College of Rheumatology (ACR) criteria.

*EULAR response of moderate or good, based on DAS28-CRP.

${ }^{\dagger}$ DAS28-CRP score less than 2.6.

${ }^{\ddagger}$ Change from baseline $\mathrm{HAO}-\mathrm{Dl}$ score of 0.22 or greater.

${ }^{\S}$ Negative change represents an improvement. Patient numbers assessed: placebo $(n=130)$; ofatumumab $(n=126)$.

**Patient numbers assessed: placebo $(n=117)$; ofatumumab $(n=116)$.

"Patient numbers assessed: placebo ( $n=111)$; ofatumumab $(n=114)$.

Results are reported in accordance with EULAR/ACR collaborative recommendations. ${ }^{33}$

CRP, C-reactive protein; DAS28, disease activity score based on 28 joints; EULAR, European League Against Rheumatism; ESR, erythrocyte sedimentation rate; FACIT-F, functional assessment of chronic illness therapy-fatigue; HAO-DI, health assessment questionnaire disability index; SF-36, short-form health survey.

the ACR20 response in ofatumumab and placebo groups, respectively, was $50 \%(56 / 111)$ versus $26 \%(29 / 113)$ for seropositive patients and $44 \%(7 / 16)$ versus $31 \%(5 / 16)$ for seronegative patients.

All other secondary efficacy endpoints, including EULAR response and mean change from baseline in DAS28-CRP and DAS28-ESR were significantly improved in the ofatumumab group compared with placebo, except for clinical remission (DAS28-CRP <2.6) (table 2 and supplementary table S1, available online only). The mean change from baseline in DAS28-CRP scores over the 24-week period showed sustained improvement compared with placebo from week 8 to week 24 (figure 3). Ofatumumab also provided improvements in patient-reported outcomes as shown by significantly greater changes from baseline in HAQ-DI, FACIT-F and SF36v2 scores compared with placebo (table 2).

\section{Laboratory findings}

Peripheral B lymphocytes (CD19) were greatly reduced at each visit relative to baseline in the ofatumumab group: median reductions at weeks 2 (before the second infusion), 4, 12 and 24 were $95 \%, 96 \%, 96 \%$ and $94 \%$, respectively. In the placebo group, CD19 cells increased by $3 \%$ at week 24 . In the ofatumumab group one patient $(1 \%)$ had a CD19 B-cell count equal to or greater than the lower limit of normal $(0.11 \mathrm{GI} / \mathrm{l})$ or the baseline value at week 24 . No trend for a change in peripheral CD3, CD4 or CD8 T-cell counts was observed in either group.

\section{Biomarkers and assessment of immunogenicity}

At week 24, the median change from baseline in absolute biomarker levels for ofatumumab and placebo, respectively, were: -4.0 versus $-0.4 \mathrm{ng} / \mathrm{l}$ for IL-6; -53.5 versus $-10.9 \mathrm{mg} / \mathrm{ml}$ for serum amyloid $A ;-138$ versus 0 units for anti-CCP; -6.3 versus 0.0 units for RF-IgM; -4.8 versus 0.0 units for RF-IgG and -3.0 versus 0.0 units for RF-IgA. At week 24, the median change from baseline in immunoglobulin levels for ofatumumab and placebo, respectively, were: -1.30 versus $-0.60 \mathrm{~g} / \mathrm{l}$ for $\mathrm{IgG}$; -0.30 versus $-0.02 \mathrm{~g} / 1$ for IgM and -0.23 versus $-0.09 \mathrm{~g} / \mathrm{l}$ for IgA. A small number of patients on ofatumumab or placebo had immunoglobulins equal to or less than the lower limit of normal during the study (IgM 6 vs 4; IgG 3 vs 1; IgA, no patients, respectively). No patients treated with ofatumumab developed detectable anti-ofatumumab antibodies at week 24 . 


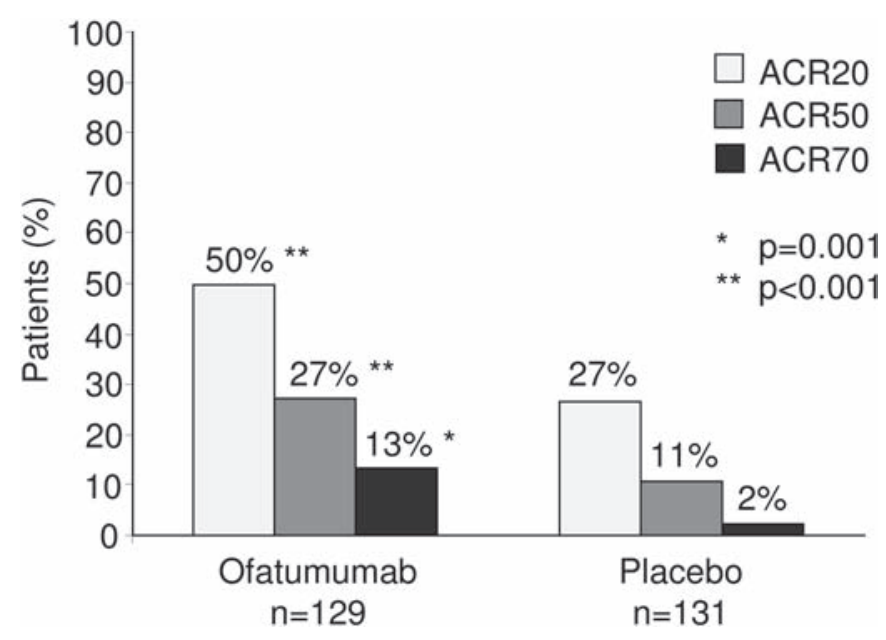

Figure 2 ACR 20/50/70 responses at week 24 in patients receiving ofatumumab $700 \mathrm{mg}$ or placebo. ACR20/50/70, 20\%/50\%/70\% improvement as per American College of Rheumatology (ACR) criteria.

\section{Safety}

The overall incidence of $\mathrm{AE}$ was $89 \%$ and $55 \%$ in ofatumumab and placebo groups, respectively (table 3). Within the ofatumumab group the most commonly reported $\mathrm{AE}$ were rash $(21 \%)$ and urticaria $(12 \%)$; these events mostly occurred on the day of first infusion (19\% and $12 \%$, respectively). The proportion of patients experiencing an infusion-related $\mathrm{AE}$ on the day of first infusion was $68 \%$ for ofatumumab and $6 \%$ for placebo; infusion-related $\mathrm{AE}$ on the day of second infusion markedly declined ( $<1 \%$ and $0 \%$, respectively). Most AE were of mild or moderate intensity. Severe AE were reported for $8 \%$ of patients on ofatumumab and $2 \%$ on placebo, with $5 \%$ and less than $1 \%$ occurring on the day of first infusion. AE leading to withdrawal were $9 \%$ for ofatumumab and less than $1 \%$ for placebo. Four SAE (bacterial gastroenteritis, pneumonia, myocardial infarction, ischaemic stroke) were reported for four patients $(3 \%)$ in the placebo group and seven SAE (angioedema, interstitial lung disease (fatal), synovitis, pulmonary embolism, diarrhoea and pneumonia, pericardial effusion) were reported for six patients $(5 \%)$ in the ofatumumab group. Two of these SAE (angioedema, pneumonia), both in the ofatumumab group, were considered by the investigator to be related to the investigational product. There was one fatal SAE of interstitial lung disease in the ofatumumab group, which was not considered by the investigator to be related to the investigational product but to RA worsening.

AE within the system organ class of infections and infestations were reported for $26 \%$ and $32 \%$ of patients on placebo and ofatumumab, respectively. None of the events was of severe intensity and none led to discontinuation of the investigational product or withdrawal from the study. One SAE of pneumonia was reported in each group and one SAE of bacterial gastroenteritis was reported on placebo (table 3). No serious opportunistic infections and no cases of progressive multifocal leukoencephalopathy were reported. Two neoplasms, both prostatic adenoma and both in the placebo group, were reported.

\section{DISCUSSION}

The results from the 24-week, placebo-controlled, double-blind phase of this trial confirm the previously reported efficacy of one course of intravenous ofatumumab in active RA. ${ }^{11}$ In addition, this study provides further information on the efficacy
Table 3 Safety of placebo and ofatumumab over 24 weeks (safety population)

\begin{tabular}{|c|c|c|}
\hline & \multicolumn{2}{|l|}{ Patients with AE, n (\%) } \\
\hline & $\begin{array}{l}\text { Ofatumumab } 700 \mathrm{mg} \\
(\mathrm{n}=130)\end{array}$ & Placebo $(n=130)$ \\
\hline Total patient-years of exposure & 57 & 58 \\
\hline Any AE & $116(89)$ & $71(55)$ \\
\hline Any SAE (fatal or non-fatal)* & $6(5)$ & $4(3)$ \\
\hline Death & $1(<1)$ & 0 \\
\hline $\begin{array}{l}\text { AE leading to discontinuation of IP or } \\
\text { withdrawal from study }\end{array}$ & $12(9)$ & $1(<1)$ \\
\hline \multicolumn{3}{|l|}{ Most common $A E$ ( $\geq 5 \%$ in either group) } \\
\hline Rash & $27(21)$ & $1(<1)$ \\
\hline Urticaria & $16(12)$ & $1(<1)$ \\
\hline Urinary tract infection & $7(5)$ & $9(7)$ \\
\hline Headache & $6(5)$ & $8(6)$ \\
\hline Nasopharyngitis & $10(8)$ & $3(2)$ \\
\hline Pruritus & $10(8)$ & $2(2)$ \\
\hline Throat irritation & $10(8)$ & $1(<1)$ \\
\hline Hypersensitivity & $8(6)$ & 0 \\
\hline Dyspnoea & $7(5)$ & 0 \\
\hline \multicolumn{3}{|l|}{ Infusion reactions } \\
\hline Any AE on day of first infusion & $92(71)$ & $12(9)$ \\
\hline Infusion-related reaction ${ }^{\dagger}$ & $89(68)$ & $8(6)$ \\
\hline Any $A E$ on day of second infusion & $4(3)$ & $4(3)$ \\
\hline Infusion-related reaction ${ }^{\dagger}$ & $1(<1)$ & 0 \\
\hline Patients with an infection & $42(32)$ & $34(26)$ \\
\hline No of infections & 60 & 45 \\
\hline Infections/100 patient-years (95\% Cl) & $\begin{array}{l}105.26 \text { (81.86 to } \\
135.49)\end{array}$ & $\begin{array}{l}77.59 \\
(58.07 \text { to } 103.82)\end{array}$ \\
\hline Patients with a serious infection & $1(<1)$ & $2(2)$ \\
\hline No of infections & 1 & 2 \\
\hline Infections/100 patient-years $(95 \% \mathrm{Cl})$ & 1.75 (0.42 to 9.77$)$ & $\begin{array}{l}3.45 \\
(1.07 \text { to } 12.46)\end{array}$ \\
\hline \multicolumn{3}{|l|}{ Cardiac disorders } \\
\hline Any & $7(5)$ & $6(5)$ \\
\hline Serious & $1(<1)$ & $1(<1)$ \\
\hline \multicolumn{3}{|l|}{ Vascular disorders } \\
\hline Any & $12(9)$ & $8(6)$ \\
\hline Serious & 0 & 0 \\
\hline \multicolumn{3}{|l|}{ Neoplasms (benign or malignant) } \\
\hline Any & 0 & $2(2)$ \\
\hline Serious & 0 & 0 \\
\hline
\end{tabular}

*SAE were bacterial gastroenteritis, pneumonia, myocardial infarction, ischaemic stroke in the placebo group and angioedema, interstitial lung disease (fatal, unrelated to ofatumumab), synovitis, pulmonary embolism, diarrhoea and pneumonia, pericardial effusion in the ofatumumab group.

${ }^{\dagger}$ Infusion-related reactions (events likely to represent clinical signs and symptoms characteristic of ofatumumab infusion reactions in patients with RA) were identified by a safety review team before unblinding.

$A E$, adverse event; IP, investigational product; $R A$, rheumatoid arthritis; $S A E$, serious adverse event.

of ofatumumab in a well-defined RA patient population with long-standing disease not controlled by standard methotrexate therapy and not previously treated with other available biological DMARD therapies. Ofatumumab, at a dose of $700 \mathrm{mg}$ administered twice, added to a background stable dose of methotrexate therapy, demonstrated a significantly greater ACR20 response at week 24 (primary endpoint) compared with placebo. Significantly greater improvements were observed in key secondary endpoints such as ACR50, ACR70, change from baseline in both DAS28-CRP and DAS28-ESR, EULAR response, physical function (HAQ-DI) and fatigue (FACIT-F).

Efficacy data from seronegative RA patients, for either RF or anti-CCP, as observed in the study, should be interpreted with caution because of the small sample size. Data from a number of clinical trials with rituximab in a range of RA populations seem 


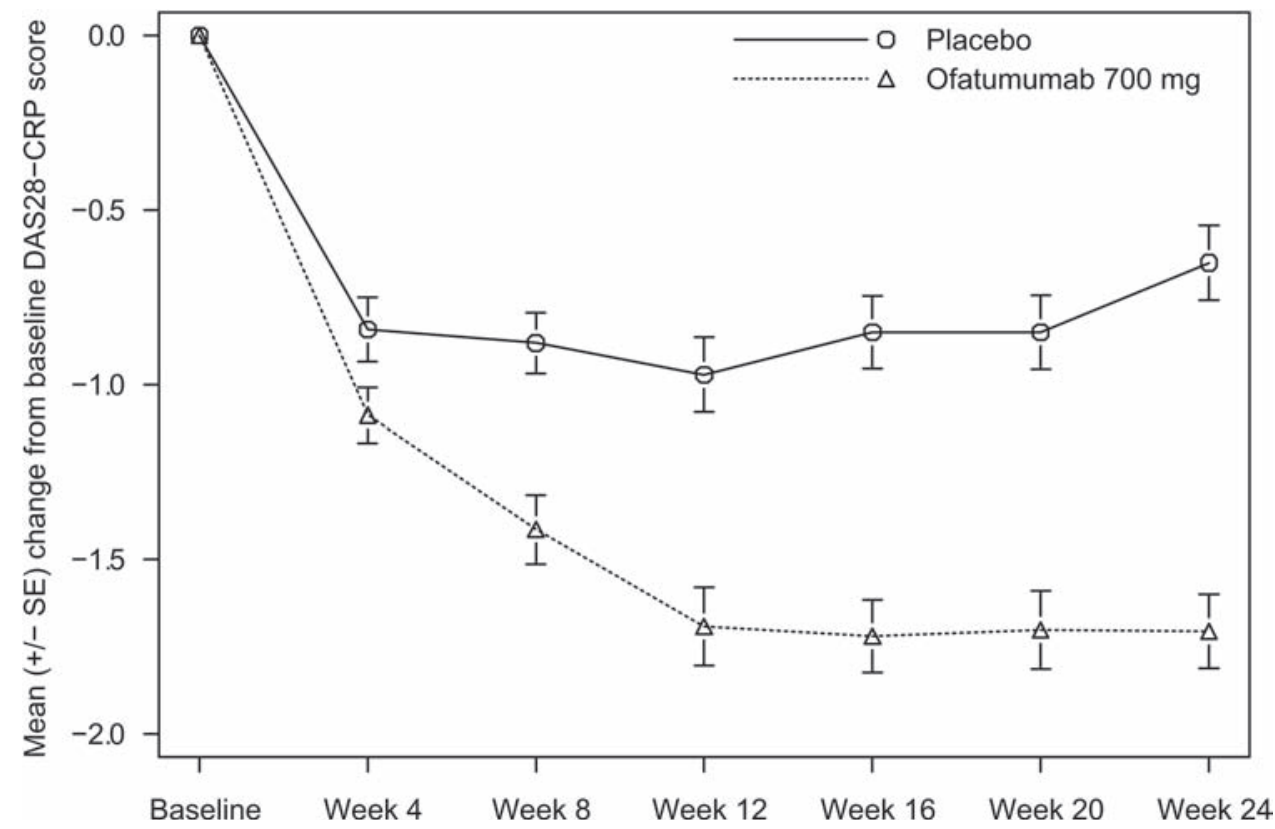

Figure 3 Mean change from baseline for DAS28 using CRP over time. CRP, C-reactive protein; DAS28, disease activity score based on 28 joints.

to suggest that seropositive patients (RF and/or anti-CCP) have a higher likelihood of response to B-cell-depleting therapy compared with seronegative patients, in particular for improving signs and symptoms; ${ }^{18-22}$ however, the statistical significance of these findings remains to be determined. Radiographic endpoints were not assessed in this ofatumumab trial and data are not currently available for the persistence of response beyond 24 weeks.

The safety information gathered in this study is consistent with that observed in short-term studies of rituximab in active RA. ${ }^{182324}$ Although a greater proportion of patients receiving ofatumumab experienced mild to moderate infusion-related reactions on the day of first infusion, despite steroid premedication, less than $1 \%$ of ofatumumab patients experienced an infusion-related reaction on the day of second infusion. This finding may be explained by the sudden cytokine release that follows the pronounced B-cell lysis occurring after CD20 ligation, as previously reported in non-Hodgkin's lymphoma patients treated with rituximab. ${ }^{25}$ The rate of serious infections in patients treated with ofatumumab was low and comparable to placebo. Although progressive multifocal leukoencephalopathy has been reported with rituximab, ${ }^{26}$ no such cases were identified with ofatumumab in the current small study of limited duration, which excluded patients who screened positive for JC virus DNA at baseline (one patient excluded). Similarly, serious opportunistic infections were reported in ocrelizumab trials, but were not observed in this study. ${ }^{27} 28$

Ofatumumab is a fully human $\mathrm{mAb}$, thereby offering a low immunogenicity potential. Although all patients in the study were on methotrexate, which may suppress the development of antidrug antibodies, ${ }^{29}$ and patients only received one course of treatment over 24 weeks, no anti-ofatumumab antibodies were detectable in any of the treated patients. In contrast, $7.9 \%$ and $5.4 \%$ of RA patients who received the chimeric $\mathrm{mAb}$ rituximab $500 \mathrm{mg}$ administered twice and $1000 \mathrm{mg}$ administered twice, respectively, in a study of a similar patient population, developed human antichimeric antibodies at 24 weeks. ${ }^{19}$ Overall, $11 \%$ of patients with RA have tested positive for auto-antibodies at any time after receiving rituximab. ${ }^{26}$ There was no reported correlation between the development of these human antichimeric antibodies and safety or efficacy; nevertheless, the possibility of loss or reduction of efficacy, local reactions, serum sickness/immune complex-mediated disease and major allergic reactions (eg, urticaria, bronchospasm, bronchoconstrictions) is well recognised. ${ }^{30}$ In addition to its efficacy in RA demonstrated in this trial, ofatumumab is approved for the treatment of refractory chronic lymphocytic leukaemia. ${ }^{31}$ The mechanism of B-cell tumour lysis is probably through the activation of both complement-dependent cytotoxicity and antibody-dependent cell-mediated cytotoxicity. Compared with rituximab, ofatumumab demonstrates increased binding of $\mathrm{C} 1 \mathrm{q}$ and more potent complement-dependent cytotoxicity, even in chronic lymphocytic leukaemia cells with low CD20 expression levels. ${ }^{32}$ It is unknown at this time, however, whether these mechanistic differences can translate to improved safety, tolerability, efficacy, or potency over rituximab.

In summary, ofatumumab is a fully human $\mathrm{mAb}$ binding an epitope of CD20 distinct to that recognised by rituximab. A single course of two infusions of $700 \mathrm{mg}$ was efficacious and safe in biological-naive, active RA patients on background methotrexate up to 24 weeks after treatment. As expected for a fully human $\mathrm{mAb}$, ofatumumab did not induce immunogenicity.

Acknowledgments The authors would like to thank all participating investigators and their staff who provided and cared for patients and collected data for the study: Argentina: E Lucero, 0 Rillo, D Siri, I Strusberg, J Velasco; Australia: S Hall, P Nash, P Youssef; Chile: M Aliste, R Jimenez, P Miranda, F Radrigan, N Stevensen; Czech Republic: L Bortlik, J Vencovsky, P Vitek; Hungary: B Rojkovich, F Szanyó, E Vereckei; Peru: E Cabello, 0 Castañeda; Poland: S Jeka, A Racewicz, Z Ruzga, A Sawicki; Romania: C Zainea; Russian Federation: 0 Ershova, 0 Lesnyak, E Nasonov, T Polikarpova, A Rebrov; Spain: RA Blanco, VR Valverde, MI Oyarzabal, FN Sarabia; UK: A Hammond, T Sheeran.

Funding This study was sponsored and funded by Genmab and GlaxoSmithKline under a collaborative agreement.

Competing interests Genmab and GlaxoSmithKline provided financial support to the institutions that participated in this study. PCT has received research grants from Merck, UCB, AstraZeneca, GlaxoSmithKline and Roche and has been an invited speaker and advisor for Abbott, Bristol-Myers Squibb, Centocor, Roche, Schering-Plough, Wyeth (acquired by Pfizer in October 2009), Genmab, 
GlaxoSmithKline and UCB. EQ, SM, RK and DJC are employees of GlaxoSmithKline and own stock in GlaxoSmithKline. JP was formerly employed at Genmab and owned Genmab stocks.

\section{Patient consent Obtained.}

Contributors Helle Kastberg and Soren Tamer (Genmab) provided advice on study design. Peter Critchley, Shilpa Vadher and Janet Perkins (GlaxoSmithKline) provided clinical operations, data management and programming support. EO (GlaxoSmithKline), clinical investigation leader and medical monitor of this trial, authored the manuscript. Editorial support (writing assistance, assembling tables and figures, collating author comments, grammatical editing, and referencing) was provided by Julie Taylor of Peak Biomedical Ltd, Macclesfield, UK and was funded by GlaxoSmithKline.

Ethics approval All participating sites received approval from national, regional, or investigational centre ethics committee or institutional review boards, as appropriate.

Provenance and peer review Not commissioned; externally peer reviewed.

\section{REFERENCES}

1. Teeling JL, Mackus WJ, Wiegman LJ, et al. The biological activity of human CD20 monoclonal antibodies is linked to unique epitopes on CD20. J Immunol 2006;177:362-71.

2. Genovese MC, Kaine JL, Lowenstein MB, et al. Ocrelizumab, a humanized anti-CD20 monoclonal antibody, in the treatment of patients with rheumatoid arthritis: a phase $\mathrm{l} / \mathrm{I}$ randomized, blinded, placebo-controlled, dose-ranging study. Arthritis Rheum 2008;58:2652-61.

3. Goldenberg DM, Rossi EA, Stein R, et al. Properties and structure-function relationships of veltuzumab (hA20), a humanized anti-CD20 monoclonal antibody. Blood 2009; 113:1062-70.

4. Teeling JL, French RR, Cragg MS, et al. Characterization of new human CD2O monoclonal antibodies with potent cytolytic activity against non-Hodgkin lymphomas. Blood 2004;104:1793-800.

5. Cragg MS, Walshe CA, Ivanov AO, et al. The biology of CD20 and its potential as a target for mAb therapy. Curr Dir Autoimmun 2005;8:140-74.

6. Glennie MJ, French RR, Cragg MS, et al. Mechanisms of killing by anti-CD20 monoclonal antibodies. Mol Immunol 2007;44:3823-37.

7. Bleeker WK, Munk ME, Mackus WJ, et al. Estimation of dose requirements for sustained in vivo activity of a therapeutic human anti-CD2O antibody. $\mathrm{Br} \mathrm{J}$ Haematol 2008;140:303-12.

8. Beum PV, Lindorfer MA, Beurskens F, et al. Complement activation on B lymphocytes opsonized with rituximab or ofatumumab produces substantial changes in membrane structure preceding cell lysis. J Immunol 2008;181:822-32.

9. Pawluczkowycz AW, Beurskens FJ, Beum PV, et al. Binding of submaximal C1q promotes complement-dependent cytotoxicity (CDC) of B cells opsonized with anti-CD20 mAbs ofatumumab (OFA) or rituximab (RTX): considerably higher levels of CDC are induced by OFA than by RTX. J Immunol 2009;183:749-58.

10. Saphire E0, Stanfield RL, Crispin MD, et al. Contrasting lgG structures reveal extreme asymmetry and flexibility. J Mol Biol 2002;319:9-18

11. Ostergaard $\mathbf{M}$, Baslund B, Rigby W, et al. Ofatumumab, a human anti-CD20 monoclonal antibody, for treatment of rheumatoid arthritis with an inadequate response to one or more disease-modifying antirheumatic drugs: results of a randomized, double-blind, placebo-controlled, phase l/II study. Arthritis Rheum 2010;62:2227-38.

12. Felson DT, Anderson JJ, Boers M, et al. American College of Rheumatology. Preliminary definition of improvement in rheumatoid arthritis. Arthritis Rheum 1995;38:727-35

13. van Gestel AM, Prevoo ML, van 't Hof MA, et al. Development and validation of the European League Against Rheumatism response criteria for rheumatoid arthritis. Comparison with the preliminary American College of Rheumatology and the World Health Organization/International League Against Rheumatism Criteria. Arthritis Rheum 1996;39:34-40.

14. Prevoo ML, van 't Hof MA, Kuper HH, et al. Modified disease activity scores that include twenty-eight-joint counts. Development and validation in a prospective longitudinal study of patients with rheumatoid arthritis. Arthritis Rheum 1995;38:44-8.

15. Felson DT, Anderson JJ, Boers M, et al. The American College of Rheumatology preliminary core set of disease activity measures for rheumatoid arthritis clinical trials. The Committee on Outcome Measures in Rheumatoid Arthritis Clinical Trials. Arthritis Rheum 1993;36:729-40.

16. Cella D, Yount S, Sorensen M, et al. Validation of the Functional Assessment of Chronic IIIness Therapy Fatigue Scale relative to other instrumentation in patients with rheumatoid arthritis. J Rheumatol 2005;32:811-19.

17. Arnett FC, Edworthy SM, Bloch DA, et al. The American Rheumatism Association 1987 revised criteria for the classification of rheumatoid arthritis. Arthritis Rheum 1988;31:315-24.

18. Cohen SB, Emery P, Greenwald MW, et al. Rituximab for rheumatoid arthritis refractory to anti-tumor necrosis factor therapy: results of a multicenter, randomized, double-blind, placebo-controlled, phase III trial evaluating primary efficacy and safety at twenty-four weeks. Arthritis Rheum 2006;54:2793-806.

19. Emery P, Deodhar A, Rigby WF, et al. Efficacy and safety of different doses and retreatment of rituximab: a randomised, placebo-controlled trial in patients who are biological naive with active rheumatoid arthritis and an inadequate response to methotrexate (Study Evaluating Rituximab's Efficacy in MTX iNadequate rEsponders (SERENE)). Ann Rheum Dis 2010;69:1629-35.

20. Rubbert-Roth A, Tak PP, Zerbini C, et al. Efficacy and safety of various repeat treatment dosing regimens of rituximab in patients with active rheumatoid arthritis: results of a phase III randomized study (MIRROR). Rheumatology (Oxford) 2010;49:1683-93.

21. Tak PP, Rigby WF, Rubbert-Roth A, et al. Inhibition of joint damage and improved clinical outcomes with rituximab plus methotrexate in early active rheumatoid arthritis: the IMAGE trial. Ann Rheum Dis 2011;70:39-46.

22. Isaacs JD, Olech E, Tak PP, et al. Autoantibody-positive rheumatoid arthritis (RA) patients (pts) have enhanced clinical response to rituximab (RTX) when compared with seronegative patients [abstract]. Ann Rheum Dis 2009;68(Suppl3):442.

23. Edwards JC, Szczepanski L, Szechinski J, et al. Efficacy of B-cell-targeted therapy with rituximab in patients with rheumatoid arthritis. N Engl J Med 2004:350:2572-81.

24. Emery P, Fleischmann R, Filipowicz-Sosnowska A, et al. The efficacy and safety of rituximab in patients with active rheumatoid arthritis despite methotrexate treatment: results of a phase IIB randomized, double-blind, placebo-controlled, dose-ranging trial. Arthritis Rheum 2006;54:1390-400.

25. van der Kolk LE, Grillo-López AJ, Baars JW, et al. Complement activation plays a key role in the side-effects of rituximab treatment. Br J Haematol 2001:115:807-11.

26. Genentech. Rituxan (rituximab) Prescribing Information, 2011. http://www.gene.com/ gene/products/information/pdf/rituxan-prescribing.pdf (accessed 26 January 2011).

27. Emery P, Rigby WFC, Tak PP, et al. Serious infections with ocrelizumab in rheumatoid arthritis: pooled results from double-blind periods of the ocrelizumab phase III RA program [abstract]. Arthritis Rheum 2010;62(Suppl 10):414.

28. Rigby WFC, Tony HPT, Oelke KR, et al. Efficacy and safety of ocrelizumab in patients with active rheumatoid arthritis who had an inadequate response to methotrexate: results from the phase III STAGE trial [abstract]. Arthritis Rheum 2010;62(Suppl 10):383.

29. Maini RN, Breedveld FC, Kalden JR, et al. Therapeutic efficacy of multiple intravenous infusions of anti-tumor necrosis factor alpha monoclonal antibody combined with low-dose weekly methotrexate in rheumatoid arthritis. Arthritis Rheum 1998:41:1552-63.

30. European Medicines Agency. Draft Guideline on Immunogenicity Assessment of Monoclonal Antibodies Intended for In Vivo Clinical Use. EMA/CHMP/ BMWP/86289/2010, 2010. http://www.ema.europa.eu/docs/en_GB/document library/Scientific guideline/2010/11/WC500099362.pdf (accessed 26 January 2011).

31. GlaxoSmithKline. Arzerra (ofatumumab) Prescribing Information, 2010. http://us.gsk. com/products/assets/us arzerra.pdf (accessed 26 January 2011).

32. Wierda WG, Kipps TJ, Mayer J, et al. Ofatumumab as single-agent CD20 immunotherapy in fludarabine-refractory chronic lymphocytic leukemia. J Clin Oncol 2010;28:1749-55.

33. Aletaha D, Landewe R, Karonitsch T, et al. Reporting disease activity in clinical trials of patients with rheumatoid arthritis: EULAR/ACR collaborative recommendations. Ann Rheum Dis 2008;67:1360-4. 